International Journal of Social Science And Human Research

ISSN(print): 2644-0679, ISSN(online): 2644-0695

Volume 04 Issue 01 January 2021

DOI: $10.47191 / \mathrm{ijsshr} / \mathrm{v} 4-\mathrm{i} 1-01$

Page No : 01-09

\title{
Issues in E-Learning during Covid-19 in Morocco: A Focus on EFL Master Students' Voices
}

\author{
Abdelmajid JAMIAI \\ Hassan First University, Faculty of Languages, Arts and Human Sciences Settat- Morocco
}

\begin{abstract}
E-learning has recently been given much attention in Higher Education (HE) in Morocco. This article has to do with students' reflections on using technology in online classes for one semester during the emergency of Covid-19 pandemic. The research design for this study is qualitative in which unstructured interview was used to collect data from thirty-two Master Program students at the Faculty of Letters and Human Sciences of Dhar Mehraz at Sidi Mohamed Ben Abdellah University in Morocco as a convenient sampling. The thematic analysis was used to analyze the retrieved data via e-mails. The findings of this study indicate that online learning for master students in Morocco was not as effective as in face-to-face instructions. It was also found that master students encountered many challenges in online classes during the unexpected circumstances of the pandemic due to the unpreparedness of the educational system, which paves the way to some recommendations in the field of online teaching/learning classes.
\end{abstract}

KEY-WORDS: E-learning, Covid-19, platform, educational technology, face-to-face instruction

\section{INTRODUCTION}

Since the outbreak of Covid-19 pandemic in many parts of the world, particularly in Morocco, there has been a race in policy making to cope with the unexpected phenomenon. In the field of education, stakeholders have agreed upon many preventive measures to keep practitioners and the educational system with strong immunity and reduce the number of attacked people by the Corona virus. In the same vein, e-learning was suggested as a substitute of face-to-face classroom to keep the academic continuity.

After having closed higher schools, faculties and other educational institutions in Morocco on March 15, 2020, the Prime Minister of the government, the Minister of National Education, Higher Education and Scientific Research, the Delegate Minister taking charge of Higher Education and Scientific Research, University Presidents, Deans of faculties and Directors of Higher Schools have dealt with the emergency of Covid-19 by resorting to online/ distance education. Moreover, activists of the civil society, parents, teachers and students have shown low resistance to the taken decision to go online. Thus, running after the benefits of their students, professors have accepted to use online platforms and other soft applications, with the means they have had, so that no student should be left behind.

In the next stage and to overcome some of the limitations imposed by other external factors and to guarantee the quality of distance education, Television channels and the radio have been used to make up for the challenges. The first reaction to the new policy of innovative pedagogy had to with the infrastructure. Then, echoes emerging from complaints of social classes came to the surface. Later on, the lack and the cost of the technical equipment could hinder the process of online teaching/learning. Besides, students' voices were sometimes silenced due to the general circumstances the country was going through. In brief, practitioners started to change their attitudes by formulating negative impressions towards the way the educational system was dealing with the pandemic. Yet, within this online learning framework, instructors and students have shown their commitment and responsibility despite the previously mentioned restrictions.

\subsection{Literature Review}

During the pandemic of Covid-19, a growing number of universities and schools of higher education have adopted distance education to share course content with their students. Keegan (1980) defines distance education as "a planned learning experience or method of instruction characterized by quasi-permanent separation of the instructor and learner(s). Within a distance education system, information and communication are exchanged through print or electronic communications media" (Keegan, 1980). This means that the aim of distance education is to deliver a course among university professors and students who are geographically distant. To achieve this goal, different media tools have been used to mediate the shared knowledge between professors, students 


\section{Issues in E-Learning during Covid-19 in Morocco: A Focus on EFL Master Students' Voices}

and the content. In this respect and within the unexpected circumstances of Covid-19, distance education implementation is to serve the academic continuity and to keep up with the agenda set by higher education institutions.

For Fillip (2011), "distance education is also a broad approach characterized by a high degree of variation. Such variation includes the types of media or technology used (print, radio, computer); the nature of the learning (workshop, seminar, degree program, supplement to traditional classroom, levels of support); institutional settings; topics addressed; and levels of interactivity support (face-to-face, online, blended, none)" (Fillip, 2001). This evokes that distance education is a method of teaching and learning via different ways that suit the commitment of students who are not able to join face-to-face classes. Distance education takes different forms, starting from printed documents that can be sent to leaners' addresses. Moreover, the radio is also used to disseminate the latest information and the course content. But in the recent years, the computer has been integrated to facilitate not only communication among professors and learners and among learners themselves but also content comprehension. In this respect, the computer with its affordances has occupied a central position as a means of instruction. Activities like organizing online seminars (webinars) and workshops are progressively scheduled either to complement or to substitute face-to-face instruction. In his definition of distance education, Phillip raised many issues that characterize the adoption of this new pedagogy. One of these is the support of the levels of interactivity, meaning that the degree of interaction varies from one medium to another. Online interaction has recently created a hot debate among practitioners in the field of education. There are views that underestimate distance learning at the level of interaction, stating that interaction is still low among learners and professors and content. However, others state that distance education paves the way to scattered learners to interact with each other. In brief, the computer creates interaction but with different levels in relation to one-to-one and one-to-many.

UNESCO defines distance education as "an educational process and system in which all or a significant proportion of the teaching is carried out by someone or something removed in space and time from the learner" (UNESCO, 2007). This would imply that distance learning is the arrangement of classes via a digitalized structure. In such area, the operation of teaching and learning is supported by the human and the medium that build a virtual learning environment separated from the real presence of learners in due time. Distance education is mainly embodied in being flexible in both time and place, which brings about diversified learning opportunities. This is to acknowledge that distance education features could be of some help for university professors and students to carry out the needed requirements to achieve the educational objectives despite being criticized for its physical separation between the teacher and the learners. Therefore, teaching in distance education is based on teaching students as individuals and not as one group. Above all, distance education remains controversial in theory in the sense that views disagree upon its reliability in comparison to face-to-face instruction.

\subsection{Motivation:}

During the emergency Covid-19 pandemic, educational institutions, mainly in higher education in Morocco, suggest online learning for Master Program students to save the academic year. After the researcher had been invited to speak twice about issues in applied language and professional development, the idea of conducting a study on students' new experience with online learning came as a motivation. The commitment of the researcher in the series of Webinars set for the Spring session of 2020 made him present with that community via Zoom Application. The researcher used to receive an ID and a password or a link to join online classes. This raised the researcher's thinking of investigating students' online behaviours with the focus on the internal and external factors that influenced their experience with the new imposed pedagogy and its expectations. Thus, the study is motivated by the existing gap in examining online learning in the Moroccan higher education context.

\subsection{Purpose:}

The purpose of this qualitative study is to detect the challenges facing the online learning in its early stages and to report students' voices as recommendations for stakeholders to take into account in the implementation of e-learning in higher education as an official new version in education in Morocco. Specifically, the study tries to accomplish the following objectives: (1) to investigate students' experiences in online courses; (2) extract and categorize findings from students' replies into themes (3) analyaze the findings thematically and (4) come up with the implications of the findings either from the students or the researcher's side for practitioners and decision-makers in the field of higher education.

\subsection{Question for research:}

Conducting any supposed study necessitates research questions by which the research objectives would be achieved. In this study, the following three research questions were addressed:

1- How did master students in Morocco perceive online learning for one semester during the pandemic of Covid-19?

2- What online learning challenges did master students in Morocco encounter during Covid-19 pandemic?

3- What are the measures to be taken to improve the quality of e-learning in the Moroccan context?

\section{METHODOLOGY}

Obviously, conducting a study aims at solving some of the problems related to an educational issue through scientific ways. The methodology adopted for this study is the qualitative approach in which the unstructured interview was used to collect qualitative 


\section{Issues in E-Learning during Covid-19 in Morocco: A Focus on EFL Master Students' Voices}

data from respondents. The participants of this study are thirty-two (32) students enrolled in two Master Programs, Applied Language Studies and Research in Higher Education and Language, Communication, and Society students at the faculty of letters and Human Sciences of Dhar Mehraz of Sidi Mohamed Ben Abdellah University in Morocco during the second half of the academic year 2019-2020 (session of Spring). The participants followed their classes remotely due to the unexpected Covid-19 pandemic. As a preventive measure, the online mode of delivery was adopted to guarantee the academic continuity in Higher Education in Morocco. For this aim, online courses took two main different forms: 1- The use of flipped classes in which instructors share documents before they meet on a specific time online to reflect on them. 2- The use of synchronous online presentation assignments in which master students deliver their presentations in parallel with inviting some experts in the field as guest speakers, which was a good opportunity for them to share and exchange knowledge related to their field of study. Data were collected via sending the unstructured interview to respondents' e-mails in a word format to facilitate writing more replies to the following one question "According to your experience with online learning during Covid-19 pandemic for one semester, what challenges did you encounter and what measures you would suggest to better ameliorate the e-learning process?".

Before analyzing the data, they were gathered, deconstructed and categorized into the following major themes: 'Feedback', 'Connectivity ', 'Attitude', 'Cost', 'Anxiety', 'Teacher Time Talk - TTT/ Student Time Talk -- STT (Interaction)', 'Equipment', 'Network', 'Turn-taking', 'Training', 'Facilities', 'Remoteness', 'Length', 'Delivery time (flexibilty)'. In this respect, thematic analysis is used to analyze the gathered set of data to find out about the respondents' opinions, views, knowledge, experience towards and about their experience with the imposed innovative pedagogy. More specifically, the inductive approach is used to examine the interview, meaning that themes are generated from the data collected in contrast to the deductive approach in which themes are set before the start of the data analysis. The discussion and interpretation of the data include the elaboration of the accumulated findings on the basis of what was set in the theoretical background, especially in the context of Covid-19 period in Morocco.

\section{FINDINGS AND DISCUSSION}

In accordance with the findings retrieved from the synthesized data of the present qualitative study on students' experiences with online learning during Covid-19 pandemic, six main themes emerged. (1) time management, (2) connectivity, (3) interaction, (4) technical support, (5) skills and training and (6) attitudes.

\subsection{Time Management:}

The notion of time is of great importance in the teacher/learning process. Yet, one of the challenges has to do with the notion of time online: "The online meeting has almost no time limits, it can last to more than three hours and a half in one session, which makes me so tired and sometimes I have something very important to do but I was obliged to stay in the meeting" (respondent2). In other words, though media tools are flexible in time and place, the way time is exploited causes some troubles for students to go on being connected. Another declared challenge in online classes is the network expense. Respondnet2 states that: "I also had the problem of connection, I was using the $3 \mathrm{G}$ mobile data, and it was very expensive. Therefore, I found myself obliged to have the WIFI". In the same respect, students find it so hard to invest in the network since the use of $3 \mathrm{G}$ is very slow and causes a limited access, which makes some of them resort to the WIFI. In short, the online mode of delivery is demanding in terms of time and money.

Another debatable issue is online assessment. Findings indicate that learners are assessed online through the presentations they deliver and the ongoing discussions during all the online meetings they have established, which is really a new experience for Moroccan students. In this respect, stakeholders in the field of education in Morocco are still conservative towards the validity of online assessment for the lack of unified forms of how to assess so as to make it credible, especially for students who are at the final stage to get a diplomat. The respondent states that "it would have been much better if some instructors focused more on whether or not we have grasped the content of the course instead of requiring students to write summaries or reports without checking if the students truly understood the course" (Respondent30). The idea of assessing students online is very provocative in the sense that professors do not check their students' comprehension of the course. In a such case, the imposed conditions of the pandemic complicates online classes by trying to make learners autonomous but the latter are seen in the first stage as independent learners and cannot disassociate with the face-to-face pedagogy. In this sense, e-learning is implemented in a context where students have to perform well as they used to do in the physical classroom and to do many tasks at the same time, knowing that some of the respondents declare that e-learning is time-consuming and makes it hard for learners to cope with it when it comes to time management.

\subsection{Connectivity:}

A big deal of a successful e-learning requires connectivity. Though online meetings give students chance to be present online, respondent7 resumed the challenges, stating that: "I perceive online meetings to be an opportunity to exchange knowledge and ideas as these latter are to be discussed. However, there are some challenges which I deem as compulsory to mention such as the lack of facilities, connection problems, lack of training from the both sides of professors and students, the timing and duration of the meetings". To be more explicit, students are not provided with the necessary facilities to be connected and to follow online classes. 


\section{Issues in E-Learning during Covid-19 in Morocco: A Focus on EFL Master Students' Voices}

Moreover, time is uncontrollable in online classes, which implies that the length of online sessions is enduring for students. Another striking idea is training. Accordingly, both professors and students have not been trained on the new mode of delivery because the challenges seem to hinder the degree of satisfaction. Respondent7 adds that: "I am completely aware that we have to accept that technology is now normalized and is part and parcel of our life, but when the use of technological devices is taken to the extreme, it could even cause health problems". Overall, the way online mode of delivery is perceived shows that it is still perplexing in higher education in Morocco.

Findings indicate that not only students are forced to use technology in teaching the English language but professors as well. Respondent17 states that: "most teachers and students may find themselves forced to use technology as they teach and learn as it is a new environment for them". Simply put, the respondent declares that online learning is a new mode of delivery for both university professors and learners since it occurs during the emergency Covid-19 pandemic. Respondent17 adds that "many students are not provided with the strong internet connection that online courses require, and thus fail to catch up with their virtual classmates". This would imply that real online engagement in the virtual environment is not nurtured; however, students' awareness of being positive towards the new pedagogy can serve them to overcome many of the challenges.

Starting from the fact that learners play a central role in the educational operation, online learning can instill new skills and values in them. Findings indicate that if students are involved in learning, their level of satisfaction increases. According to respondent18, when professors "involve all the students in participating and sharing their ideas and opinions in order to enhance our critical and creative thinking", they are not only integrating them in the learning process but they also make online learning successful as a new pedagogy (Respondent18). More findings show that e-learning is very flexible in its asynchronous mode. Respondent 18 states that "the videos are one of the amazing resources that can be viewed anytime and from anywhere". Knowing that e-learning is both synchronous and asynchronous, synchronous classes are launched online, at the same time, when participants are in the meeting, while the asynchronous phase, off-line, is embodied in checking the archive and the saved videos that fosters flexibility of e-learning, meaning that these classes can be watched in a delayed time by using digital devices such as computers, smartphones and tablets. The respondent 18 states that "Fostering a sense of community in online classes will make the learning experience more meaningful for online students and help them stay connected during the life of the course".

The integration of ICT in education is a predominant factor to improve the quality of education and learners' life. Reforms and laws in Morocco have given much importance to use technology in education. For instance, when the ministry of education launches such reforms, the main target is to digitalize learning to achieve equity between members of society and to provide them with equal opportunities for a better life. Accordingly, the findings of the present study show that the infrastructure of online learning is still weak in terms of cost. Moreover, it is found that resorting to e-learning does not take students' circumstances into account. The respondent adds that "e-learning can only be a supplement to face-to-face learning" (Respondent24). This would reveal that students are still unconvinced of the swift change in the mode of delivery simply because the taken measures seek for the pedagogical continuity and the pandemic diffusion.

\subsection{Interaction:}

One of the primordial characteristics in the teaching/learning operation is interaction. Respondents' experiences with the online mode of class delivery show that professors dominate the talk. This is clear when one of respondent 3 states that "In our case, each one of us is required to deliver a presentation in only 20 minutes, which I consider as not fair enough and insufficient to express freely". This denotes that students are given less time for self-expressing, which connotes that media tools are not used democratically in the distribution of time among the participants in the online meetings. Thus, one of the main aims for which elearning is integrated in the educational process is to provide students with equal opportunities; however, students' interaction is about to be neglected or reduced by favouring professors' talk. To this extent, online classes make students feel marginalized and disregarded because of the top-down approach used by professors in higher education.

Students are not involved in the online course. Respondent4 declares that: "I would say that if all students are being listened to and being involved would be more beneficial. Promoting interaction is a key point in improving the e-learning process". For further elaboration, when students are involved, they learn collaboratively. In the same sense, online classes do not encourage collaborative learning though students belong to the same learning community in which sharing and giving feedback are so constructive.

Better learning happens when e-learning collocates with face-to-face. Findings show that "if online learning is used along with faceto-face instruction could ameliorate the teaching and learning practices" (Respondent14). This means that e-learning and face-toface modes are two faces of the same coin by considering that "online learning is a strong option that can promote learning". Yet, the same respondent goes on to state that there is no real interaction between the students and the instructor in addition to the lurkers that keep hiding behind the screen". Starting from the fact that 'interaction' is one of the units of measurement and one of the pillars upon which teaching and learning are based, online classes are accused of lacking teacher-student interaction. Moreover, instead of being active learners, students lurk by playing a watchdog role and by being passive during the online meetings. Above all, the way online classes are perceived takes different forms of benedictions and obscenities. 


\section{Issues in E-Learning during Covid-19 in Morocco: A Focus on EFL Master Students' Voices}

Another strategy in learning is interaction. Interaction varies between the teacher and students and among students themselves. The strategy of interaction can be also approached from two main contexts: online and face-to-face. Knowing that interaction in the physical classroom requires the physical presence of the instructor and the learners, interaction in the online learning environment entails their psychological presence. On this basis, findings show that the shift from the physical to the psychological is not achieved at a certain degree to satisfy the needs of learners and to realize the online course objectives. In brief, the findings indicate that online classes are impoverished in their pedagogical engineering (respondent23).

In the teaching/learning process, giving and receiving immediate feedback enables learners to develop their learning by going through its stages. Qualitative findings in the present study indicate that "one of the most beneficial means of physically being in a classroom is the response on time" (Respondent). This evokes that respondents draw critical comparisons between face-to-face instruction and online classes, stating that professors and peers' immediate feedback is low in the sense that interaction in the online environment is not satisfying and needs to be developed. Moreover, it is found that a delayed feedback is not appreciated. According to the respondent, "during face-to-face learning, a person's questions will get an immediate answer whereas online learning means waiting for a response" (Respondent25). This would confirm that the majority of respondents prefer face-to-face learning in term of the time solicited for giving illustrations to complexities students encounter during the learning process. However, the absence of or the immediate feedback online causes a kind of anxiety that absolutely impacts their mind-sets.

The flexibility option of the medium in e-learning provides learners with the opportunity to write their comments, ask questions, share their knowledge and give feedback. In this study, respondent 25 declares that "discussing issues or problems or trying to explain them in face-time with your instructor in person is much easier than typing" (Respondent25). This means that though elearning is rich in the use of media tools and provides more affordances for learners, their engagement in writing is not as efficient as in face-to-face to transmit the intended discourse. For this, leaners prefer face-to-face interaction to give feedback instead of typing when they go online as the latter makes distractions in waiting for response about a raised issue. To this end, the study shows that students' experience with/in the online environment is not nurtured with increasing their social presence online to look like real learners as they are in the physical classroom.

\subsection{Technical Support:}

Online learning in higher education is strongly based on the affordances the machine provides learners with to support their learning in a technical way. Another challenge facing students' online learning is the lack of technical equipments. Respondents continue accusing online classes to be less effective in the sense that the computer and its accessories are not able to achieve a good quality of learning online. For instance, respondent5 confesses that: “According to my experience, the most important challenge is the lack of equipment. I, for instance, have technical problem in computer, the mic is not working well and the sometimes I have 'poor' connection". This results in disconnection and absenteeism of the students. Respondent5 adds that "According to my experience, the most important challenge is the lack of equipment. I, for instance, have technical problem in computer, the mic is not working well and the sometimes I have 'poor' connection". This means that the idea that the Internet reduces distance among those who are geographically dispersed is not absolute, especially some of the students are located in rural areas where network and equipment problems are apparent.

Being a citizen of a remote area with limited access of the Internet, the student is not afforded equal online learning opportunities due to technical issues. The situation, according to the findings, "hinders their online learning process and creates inequality and disparity between students in terms of keeping up with the online study materials" (Respondent16). As it is accentuated on in the Strategic Vision 2015-2030, education in Morocco should strongly be based on 'equal opportunities'. However, in this study, online learning has created more gaps between learners descendent from geographically dispersed areas. The lack of equipment and the access to the Net do not democratize learning in the virtual environment. Another challenge respondent16 tries to back up is that professors are not skillful in the use of Information Communication Technology (ICT) and the adaptation of the innovative pedagogy. Respondent31 supports the idea, stated by respondents16, that there is a number of students who live in rural areas and who do not have access to the internet will find it challenging to join virtual classes. In brief, the reality of learning for master students does not match with the expectations of decision-makers whose intention was to make out of online learning an alternative to face-to-face instruction.

\subsection{Skills and Training:}

To manipulate the online environment tools, there must be skillful users who are well-equipped with some training in the field. Findings show that using Moodle platform is to save the academic continuity during the pandemic crisis. "E-learning was indeed the best solution in this quarantine and this gives the opportunity to master many skills as far as digital items and technological tools are concerned" (Respondent9). This indicates that though the limitations of insufficient time, training and Internet connection, elearning remains the most favored way to keep up with the crisis and its side-effects on education. Respondent 9 goes on to state that "students find it difficult and challenging (...) to attend online classes for many reasons including the basic internet connection, lack of sufficient training for example how to use some platforms such as Moodle personally speaking this is the first time I have used 


\section{Issues in E-Learning during Covid-19 in Morocco: A Focus on EFL Master Students' Voices}

such a thing so I have lacked many skills and at the same time I was somehow forced to keep with the situation and I should learn and master such skills". In addition to that, students, under pressure, seize the opportunity to chiefly improve their hard skills on the basis of having abilities to control media tools and to redirect their own learning. In brief, students are found to be self-directed learners as they acquire new skills, which raise the issue of constructivism in which learners not only build their own learning but using the learning tools as well.

One of the main challenges that would face the e-learning process is the mastery of the software use in higher education. The findings of the present study show that "some teachers and students will always find a problem or don't even know how to use a certain program" (Respondent19). During online classes via Moodle Platform or Zoom Application, university professors and students seem to be illiterate in the manipulations of such programs. Respondent20 backs up the idea of materials use stated by Respondent19 by stating that "some students did not know how to access and use online platform that was used during the pandemic". Respondent 29 backs up the idea of respondents 19 and 20 in the sense that "a lot of students do not have access to a fast internet connection. As a consequence, they fail to catch up with their classes". Thus, learning in a virtual classroom necessitates handling the soft materials so that they will assist professors and learners to achieve the objectives of the new mode of delivery and to improve the quality of higher education in Morocco. In a nutshell, online education in Morocco needs the mastery of not only the information learners are exposed to but to know how to mediate knowledge via the software, which clearly shows the unprepared governance of Covid-19 pandemic.

\subsection{Attitudes:}

The way online learning is perceived by university students affects, in a way or another, the learning process in higher education. Online classes are ineffective in comparison to face-to-face mode. According to respondent1, "I do believe that some students lack self-motivation in this regard of online learning. Therefore, those students would benefit so little from the arranged online classes which would also decrease their educational level and their creativity as well. Thus, online learning should not replace face-to-face learning; because the latter is much more effective". This means that the online mode of delivery has two main drawbacks on learners. First, it lacks self-motivation in the sense that it increases students' de-motivation. Second, it does not accelerate learning by negatively affecting their educational level and their creativity. In brief, online mode of delivery during the Covid-19 cannot replace the face-to-face mode since the latter would improve the quality of education in spite of the restrictions.

Online classes are of a great benefit for students to make connections with their ex-professors and the experts in their field of study despite the persistent challenges. According to respondent2, online learning "was a good experience; we have met our ex-teachers and benefited a lot from many experts in the field", adding that "The thing that I found challenging is participating and delivering a presentation in front of a large number of people attending the online meeting. Besides the fact that it is recorded and shared live on Facebook and posted on YouTube. This makes me anxious though I am an extrovert person". One of the challenges students may face is the presentation delivery in front of their classmates, professors and guests. Another challenge is embodied in participation, meaning that students experience a kind of anxiety due to the big number in the meeting. Moreover, the sharing and the record principles of classes on the Facebook and YouTube deepen students' anxiety by making more pressure on students to prove their linguistic and communicative competences.

E-learning strength lies in the fact of keeping the archive. According to respondent8, students are found to be urged to take notes during online classes. They are also found to read the submitted documents beforehand so that they can boost their participation effectively. In this respect, online classes are found to reflect flipped learning by providing students with what to do before the online meeting happens. By the end of the meeting, respondents are found to be able to come up with "their own synthesis that will endow them with a solid background to back up their arguments in the exam or even in their academic career later on" (Respondent8). This would imply that online learning enables students to foster their autonomous learning in which they develop their skills to construct their own meanings and share them with the members of the virtual classroom. By doing these, students are given opportunities to raise questions and react in parallel with the professor's feedback on issues related to the course.

Respondent8 declares that "effective learning habits remain the same despite the channel of teaching. This is due to the fact that learning is an independent activity that has its own universal criteria. Those criteria do not vary from one context to another because learning is a methodology and not an amount of information" (Respondent8). Further findings show that the independent phase of learning is partaken from both face-to-face and online modes of delivery in the sense that learning habits in both ways are similar in spite of the implementation of the medium because the focus should be on the 'how' and not the 'what'.

Findings of the data analysis demonstrate that the challenges some of the respondents want to convey take the form of complaints. Such a respondent's declaration 'the online learning should not be so long so as not to exceed the students' attention span and keep their concentration at a reasonable level" (Respondent10). Students are found to complain about the fluidity of time as they overwork, which makes them lose their focus on the whole session. Respondent10 also adds that "Being in a rural area where the net is weak and using $3 \mathrm{G}$ internet connection makes the online learning sometimes challenging". The problem of being connected from remote areas is inflexible in the present study because it weakens the quality of online learning. On the way round, this would indicate that students are in need of developing their soft skills by finding suitable ways to cope with the online classes and develop 


\section{Issues in E-Learning during Covid-19 in Morocco: A Focus on EFL Master Students' Voices}

these skills to find solutions to their obstacles. The same respondent is found to suggest online learning by stating that "using online learning on intermittent basis would be a great way of teaching since it is likely to meet the needs of students who prefer face to face learning and those who prefer online learning". This would indicate that the learning objectives can be achieved in online learning as well as in face-to-face instruction.

On the issue of the way e-learning and face-to-face are perceived, findings show that "e-learning complements but never replaces face-to-face learning" (Respondent11). This means that face-to-face mode is the basis in education which is founded on the physical presence of professors and students who remain the main pillars and the main actors in the real classroom. However, e-learning supplements the learning process and 'never' substitutes the physical classroom. The best cases in point are the current circumstances of Covid-19 pandemic and geographical scattering. Under such conditions, the main role of online learning is to mediate education by facilitating communication in an online learning environment.

Professors' resistance to change hinders online learning. Findings demonstrate that online classes are perceived negatively by students. One of the respondents claims that "some instructors still prefer the traditional methods of teaching", adding that "they themselves are an obstacle in enhancing e-teaching environment” (Respondent21). In this respect, learners' awareness of online practices display that the attitudes of professors towards the online learning version affects students' perceptions. In this study, professors are found, via students' views, to resist change by favoring face-to-face instruction. This naturally decreases motivation in the virtual environment, meaning that learners are facing two main obstacles: how teachers accept the transition from the physical classroom to the virtual one and the extent to which professors are able to enhance a comfortable atmosphere in the online environment.

\section{RECOMMENDATIONS}

In the present study, being aware of their new online learning, Master students' experience make them alert to suggest some recommendations they see as useful for all practitioners in the new pedagogy. Recommendations are seen from the side of the respondents and the researcher.

\subsection{By Respondents}

- To enhance learning and retain focus, I suggest that the duration of online classes should not surpass two hours (respondent26).

- $\quad$ Based on my experience with online learning, there should be a better system put in place to organize participation during a class session (respondent26).

- $\quad$ It would be appreciated if students were able to actively participate in online discussions (respondent26).

- Before using any online platform for teaching and learning, members (teachers and students) should get some basic training on manipulating the platform to better benefit from it (respondent26).

- Online learning should focus more on the quality than the quantity of the courses being delivered (respondent27).

- Students' challenges and obstacles should be given much interest in research (respondent27).

- Teacher's time talk should increase in online learning (respondent27).

- Online platforms should be used along with face-to-face classes and not just in cases of pandemic outspreads. The need for this stems from the fact that students need to switch their traditional mindset towards the acceptance of this latest wave of education. The creation of this kind of adaptability and preparedness to use the internet for educational purposes can also enhance students' computer literacy; a much needed skill in the 21st century (respondent29).

- The development of e-learning application should comply with e-safety. Educational institutions have a responsibility when it comes to keeping their students safe. Unfortunately, examples of the lack thereof during this pandemic outspread are the dozen zoom security issues (respondent29).

\subsection{By the Researcher:}

Depending on the findings obtained from the qualitatively discussed data, recommendations for stakeholders in the field of higher education, mainly during and post-Covid-19 online learning, are to be suggested. These suggestions can be divided into five main categories: (1) online behavior, (2) motivation, (3) training, (4) Connectivity and (5) hybrid education.

\subsubsection{Online behavior:}

- It would be much better to reduce the number of hours in the online session because students sometimes have more than two sessions per day. Then, it is harmful, tiring and costing in terms of time and money.

- Professors need to take interaction division (student time talk Vs teacher time talk) into consideration.

- The duration of the online sessions must be specified and should do not exceed two hours.

- Opportunities to participate in the virtual learning environment should be given to all students.

- A plausible interval of time between one session and another is highly recommended.

- Professors need to deliver online courses in short period of time

- To boost students talking time

- Long sessions decrease students' attention and attentiveness. 


\section{Issues in E-Learning during Covid-19 in Morocco: A Focus on EFL Master Students' Voices}

- Online learning is time-consuming and destructing attention.

- Digital divide should be minimized among those who attend their online classes from the urban areas and those from the countryside/ remote areas.

- Teachers need to hone their time management skills and be more creative when it comes to course delivery rather than just provide students with countless reading materials to deal with and many tasks to do.

\subsubsection{Motivation:}

- Practitioners in the field of education should help students financially for more encouragement and qualitative performance.

- Students need laptops and better internet connection to increase their social presence in the online learning community.

- The way online delivery, especially online presentations and discussions, should be cultivated among students.

- Not having access to networked computers should be taken into account. Students who have vexing Internet problems find it difficult to communicate effectively with their professors and online mates.

\subsubsection{Training:}

- Students need to take online trainings on how to learn virtually and how to manipulate the medium, learning platforms and applications.

- Professors should be trained on how to use online platforms extensively as most of them are not used to this new mode of communication and teaching.

- Professors and students need training on the use of the platform as it is an innovative pedagogy.

- Decision makers should invest in technological infrastructure and training to both professors and students.

\subsubsection{Connectivity:}

- It would be better if university professors could decide upon setting a time limit on each meeting so that students would not lose their concentration and would actually enjoy the meetings instead of getting tired of them.

- Students need to know the exact support they need for the course and for professors to take this into consideration.

\subsubsection{Hybrid education:}

- Learning is a methodology and not an amount of information, meaning that the methods of teaching online should be decided on or revisited.

- Blended learning should be included for a better and a more effective teaching/learning process.

- Findings show that online learning alone is not enough that's why blended learning should be incorporated to fill in the existing gaps in online learning.

- There should be no online assessment because it is not practical; it is far away from being reliable and it also lacks validity.

\section{CONCLUSION}

E-Learning is one of the controversial issues in Morocco during the crisis of Covid-19. Adapting online learning as a new pedagogy for Master Program students in the faculty of letters and human sciences of Dhar Lmehraz at the University of Sidi Mohammed Ben Abdellah was intended to resist to the sudden attack of the virus and to take preventive measures to limit the out-spread of the pandemic in educational institutions. Now, online learning remains debatable in education by diversifying modes of delivery and not to limit classes only in face-to-face instruction. Online learning as a new type of instruction, according to the study, can be a blessing and a curse at the same time. Though decision makers in the field of education are moving forward to implement online learning, there remain many challenges that may reverse their optimistic views. Therefore, online learning needs to be assigned the following labels: suitable infrastructure for professors and students, motivation, positive attitudes towards the swift change, the compatibility of the content to time, good governance, and effective pedagogical engineering. All the cited labels are vital to the way online classes are perceived by learners and how they relate them to their feelings and practices to conceptualize their own learning. In brief, conducting such a study using the qualitative approach cannot be generalized in the whole context of education. This would undoubtedly pave the way to deepen research from different perspectives to get to a clear image of the current situation embodied in Covid-19 pandemic.

\section{REFERENCES}

1) Burns, M. (2011). Distance education for teacher training: Modes, models and methods. Burns.-Washington: Education Development Center Inc.

2) Fillip, B. (2001). Distance education in Central America and the Caribbean: Making the most of the region's experience and tackling challenges and opportunities of the new information and communications technologies. Tokyo, Japan, and Washington, DC: Japan International Cooperation Agency.

3) Keegan, D. (1980). On defining distance education. Distance Education 1(1), 13-36.

4) UNESCO Bangkok. (2004). Integrating ICT into education: A collective case study of six Asian countries (Indonesia, Malaysia, Philippines, Singapore, South Korea, and Thailand). Retrieved from http://www.unescobkk.org/education/ict/themes/teaching-learning/trends-and-case-studies/case-studies/ 
Issues in E-Learning during Covid-19 in Morocco: A Focus on EFL Master Students' Voices

5) UNESCO Bangkok. (2007). ICT in education: Case studies from the Asia-Pacific region [PDF document]. Retrieved from http://unesdoc.unesco.org/images/0015/001567/156757e.pdf 